\title{
Pengaruh Suhu Dan Durasi Sterilisasi Metode Panas Kering Terhadap Viskositas Dan Daya Sebar Basis Gel Alginat
}

\author{
Dina Christin Ayuning Putri*, Rini DwiastutI, Sri Hartati Tuliani \\ Fakultas Farmasi, Universitas Sanata Dharma, Yogyakarta, Indonesia
}

\begin{abstract}
INFO ARTIKEL
Sejarah artikel:

Penerimaan naskah: 18

April 2017

Penerimaan naskah

revisi: 04 Agustus 2017

Disetujui untuk

dipublikasikan: 30

September 2017

\section{Kata kunci :}

daya sebar, gel alginat,

A B S T R A K

Alginat merupakan polimer alami yang dapat digunakan dalam sediaan penutup luka. Sediaan penutup luka harus steril sehingga tidak menimbulkan infeksi tambahan pada luka. Proses sterilisasi dapat mempengaruhi sifat fisik sediaan yang terkait dengan penerimaan pasien. Penelitian ini bertujuan untuk mengetahui pengaruh suhu dan durasi sterilisasi metode panas kering terhadap viskositas dan daya sebar basis gel alginat. Gel alginat disterilisasi dengan berbagai variasi suhu dan durasi kemudian diuji sifat fisiknya yang meliputi sterilitas, penampilan, viskositas, dan daya sebar. Selisih $(\Delta)$ nilai viskositas dan daya sebar basis alginat yang disterilisasi dan yang tidak disterilisasi kemudian dianalisis menggunakan uji Kruskal-Wallis ( $\Delta$ viskositas) dan ANAVA ( $\Delta$ daya sebar). Hasil penelitian ini menunjukkan bahwa suhu dan durasi sterilisasi mempengaruhi organoleptis, viskositas dan daya sebar basis gel alginat. Semakin tinggi suhu dan lama durasi sterilisasi akan menyebabkan perubahan warna menjadi lebih gelap, menurunkan viskositas dan meningkatkan daya sebar basis gel alginat, yang ditunjukkan dengan meningkatnya nilai $\Delta$ viskositas dan $\Delta$ daya sebar secara signifikan. Suhu terendah dan durasi terpendek dengan perubahan penampilan, viskositas, dan daya sebar basis gel alginat paling rendah adalah sterilisasi pada suhu $130^{\circ} \mathrm{C}$ selama 120 menit..
\end{abstract} sterilisasi, suhu,

viskositas

\section{Effect Of Temperature And Duration Of Dry Heat Sterilization Method On Viscosity And Spreadability Of Alginate-Based Gel}

Keywords:

alginat gel, spreadability, sterization, viscosity

\begin{abstract}
A B S T R ACT
Alginate is a natural polymer which can be used in preparation of wound dressing. Wound dressing preparation should be sterile so it would not cause additional infection into the wound. Sterilization process can affect the physical properties associated with patient's acceptability. The aim of this study was to examine the effect of sterilization temperature and duration using dry heat method to viscosity and spreadability of alginate-based gel. Alginate-based gel that has been sterilized with variation of temperature and duration were characterized for the sterility, viscosity and spreadability. The difference $(\Delta)$ value of viscosity and spreadability alginate-based gel, with and without sterilization was tested using Kruskal-Wallis test (for $\Delta$ viscosity) and ANOVA (for $\Delta$ spreadability). The result showed that sterilization temperature and duration affect the appearance, viscosity and spreadability of alginate-based gel. Higher temperature and duration of heating will decrease viscosity and increase spreadability of alginate-based gel, indicated by the increased value of the $\Delta$ viscosity and $\Delta$ spreadability.
\end{abstract}

* Corresponding author: Dina Christin Ayuning Putri, Fakultas Farmasi, Universitas Sanata Dharma, Paingan, Maguwoharjo, Depok,Yogyakarta 55284, 


\section{Pendahuluan}

Dalam kehidupan sehari-hari, seringkali orang mengalami luka sehingga diperlukan penanganan luka yang benar, cepat, dan tepat agar tidak terjadi infeksi lebih lanjut yang dapat memperparah luka ${ }^{1}$. Salah satu penanganan luka yang dapat diberikan adalah penutup luka (wound dressing). Sediaan penutup luka harus steril dan dapat mencegah masuknya bakteri ke dalam luka, sehingga tidak menimbulkan infeksi.

Gel merupakan salah satu sediaan penutup luka yang disukai, karena memberikan efek dingin pada saat digunakan, memberikan kelembaban, mudah dibersihkan, tidak menimbulkan residu ${ }^{2}$. Alginat adalah salah satu gelling agent alami yang digunakan untuk penutup luka ${ }^{3,4}$. Dalam pembuatan sediaan farmasi, metode sterilisasi yang sering digunakan adalah dengan pemanasan karena faktor ekonomis ${ }^{5}$.

Alginat merupakan kopolimer linear yang terbentuk dari residu asam uronat, yaitu $\beta$-D asam manuronat dan $\alpha$-L asam guluronat ${ }^{6}$. Kedua residu tersebut membentuk rantai polimer dengan adanya ion bivalen. Asam uronat akan membentuk semacam jaringan yang disebut egg box, sehingga terbentuk sistem tiga dimensi sebagai struktur gel ${ }^{7}$. Peningkatan suhu dapat mempengaruhi struktur rantai polimer pada alginat ${ }^{8}$.

Sterilisasi sediaan farmasi dan alat kesehatan dapat dilakukan dengan berbagai cara, yaitu dengan pemanasan, gas, radiasi, dan filtrasi ${ }^{9}$. Sterilisasi dengan metode panas kering digunakan untuk bahan dalam bentuk serbuk ${ }^{10}$. Berbagai usaha sterilisasi alginat telah dilakukan, misalnya menggunakan gas etilen oksida, otoklaf, dan radiasi sinar, namun proses tersebut menyebabkan kerusakan rantai polimer asam uronat pada larutan dan gel alginat ${ }^{11}$.

Sifat fisik suatu sediaan gel seperti viskositas dan daya sebar berpengaruh terhadap pengaplikasian gel dan penerimaan pasien ${ }^{12}$. Apabila gel yang dihasilkan setelah proses sterilisasi memiliki viskositas yang lebih rendah dan daya sebar yang terlalu tinggi, maka gel akan sulit diaplikasikan ${ }^{13}$.

Penelitian ini dilakukan untuk mengetahui pengaruh suhu dan durasi sterilisasi terhadap basis gel alginat dengan metode panas kering. Dengan demikian hasilnya dapat digunakan sebagai bahan pertimbangan dalam proses sterilisasi serbuk gel alginat, untuk memperoleh basis gel yang steril dengan sifat fisik sesuai.

\section{Metode}

Penelitian ini termasuk jenis penelitian eksperimental murni dengan variabel bebas adalah suhu dan durasi sterilisasi dan variabel tergantung adalah sterilitas serta sifat fisik gel alginat yaitu organoleptik, viskositas, dan daya sebar.

Alat-alat yang digunakan dalam penelitian ini adalah alat-alat gelas, oven, hot plate magnetic stirrer (CENCO), viskometer seri VT 03 (RION JAPAN), alat pengukur daya sebar (modifikasi Laboratorium Formulasi Teknologi Sediaan Farmasi USD). Bahan-bahan yang digunakan adalah natrium alginat (Bratachem), kalsium alginat (A\&Z), akuades steril, etanol 70\% (Bratachem), nutrient agar (Oxoid), Laminar Air Flow (Labconco).

\section{Preparasi dan sterilisasi basis gel alginat}

Kalsium alginat dan natrium alginat, masingmasing ditimbang sebanyak 2,5 g dan 7,5 g. Serbuk alginat disterilisasi dengan variasi suhu dan durasi seperti yang tertera pada Tabel 1 .

Tabel 1. Variasi suhu dan durasi sterilisasi

\begin{tabular}{|c|c|}
\hline Suhu $\left({ }^{\circ} \mathrm{C}\right)$ & Durasi (menit) \\
\hline 130 & $30 ; 60 ; 90 ; 120 ; 150$ \\
\hline 140 & $30 ; 60 ; 90 ; 120 ; 150$ \\
\hline 150 & $30 ; 60 ; 90 ; 120 ; 150$ \\
\hline 160 & $30 ; 60 ; 90 ; 120 ; 150$ \\
\hline 170 & $30 ; 60 ; 90 ; 120 ; 150$ \\
\hline
\end{tabular}

Serbuk alginat yang telah disterilisasi, dibuat gel dengan cara mendispersikan natrium alginat dalam $150 \mathrm{~mL}$ akuades steril (dispersi 1) dan kalsium alginat dalam $40 \mathrm{~mL}$ akuades steril (dispersi 2) secara terpisah di dalam Laminar Air Flow (LAF) dengan kecepatan aliran udara 0,4 m/detik untuk menjamin sediaan tetap steril. Campurkan kedua dispersi sampai homogen. Masing-masing perlakuan variasi suhu dan durasi sterilisasi direplikasi 3 kali.

\section{Uji sterilitas}

Uji sterilitas dilakukan dengan menggunakan media nutrien agar ${ }^{14}$. Media Nutrien agar dapat digunakan sebagai media pertumbuhan bakteri secara umum. .Media nutrient agar dibuat dengan menimbang sebanyak 28 gram serbuk nutrien agar lalu dilarutkan dalam 1 liter akuades. Media nutrien agar dipanaskan di atas hot plate magnetic stirrer sampai diperoleh larutan yang jernih. Nutrien agar diukur sebanyak $15 \mathrm{~mL}$ kemudian dituang ke dalam cawan petri. Sterilisasi media agar menggunakan otoklaf pada $121^{\circ} \mathrm{C}$ selama 15 menit, lalu dinginkan hingga memadat.

Uji sterilitas dilakukan dengan menginokulasikan basis gel alginat ke permukaan media nutrient agar secara zig-zag. Cawan petri kemudian diinkubasi pada suhu ruang selama 48 jam. Pengamatan dilakukan setelah proses inkubasi untuk melihat ada tidaknya pertumbuhan mikroba. Hasil yang diperoleh dibandingkan dengan kontrol kontaminasi media nutrient agar (tanpa aplikasi sampel untuk memastikan media nutrien agar yang digunakan steril) dan kontrol negatif (dengan aplikasi gel yang tidak disterilisasi untuk membandingkan profil sterilitas gel yang tidak mengalami sterilisasi) ${ }^{(14)}$.

\section{Uji sifat fisik}

$\underline{\text { Uji viskositas }}$

Basis gel ditimbang sebanyak $150 \mathrm{~g}$, kemudian dimasukkan ke dalam wadah stanless untuk uji viskositas. Viskometer dinyalakan hingga diperoleh nilai viskositas (dPas) ketika jarum sudah konstan pada nilai tertentu. Nilai $\Delta$ viskositas diperoleh dengan menghitung selisih viskositas antara basis gel yang disterilisasi dan yang tidak disterilisasi. 


\section{Uji daya sebar}

Basis gel ditimbang sebanyak $0,5 \mathrm{~g}$ kemudian diletakkan di tengah permukaan kaca bulat berskala. Di atas gel diletakkan kaca bulat lain lalu diberi tekanan dan beban seberat $1 \mathrm{~kg}$ selama 3 menit. Tarik kaca bulat sebelah atas dengan beban $80 \mathrm{~g}$. Jarak dan waktu yang dibutuhkan untuk memisahkan kedua kaca dicatat. Daya sebar dihitung dengan persamaan $(1)^{15}$. Nilai $\Delta$ daya sebar diperoleh dengan menghitung selisih daya sebar antara basis gel yang disterilisasi dan yang tidak disterilisasi.

Daya sebar $=\frac{\text { Berat kaca bulat atas } \mathrm{x} \text { jarak tempuh }}{\text { waktu untuk memisahkan kedua kaca }}$

\section{Analisis hasil}

Data viskositas dan daya sebar masing-masing dihitung terlebih dahulu selisih nilai antara basis gel yang mengalami sterilisasi dan tidak mengalami sterilisasi. Selisih $(\Delta)$ viskositas dan daya sebar diuji normalitasnya dengan saphiro wilk test, jika nilai $\mathrm{P}>0,05$ maka distribusi data normal (berlaku sebaliknya)

Jika distribusi data yang diperoleh normal dilakukan analisis parametrik dengan analisis varian (ANAVA), sedangkan jika distribusi data tidak normal, dilakukan analisis dengan uji Kruskal-Wallis. Analisis statistik ini dilakukan untuk mengetahui ada tidaknya pengaruh suhu dan durasi sterilisasi terhadap viskositas dan daya sebar basis alginat. Uji statistik dilakukan dengan menggunakan $\mathrm{R}$ program.

\section{Hasil}

\section{Sterilitas basis gel alginat}

Hasil uji sterilitas basis gel alginat dapat diamati pada Tabel 2. Data menunjukkan bahwa suhu dan durasi sterilisasi terendah yang dapat menghasilkan sediaan yang steril adalah $130^{\circ} \mathrm{C}$ selama 120 menit.

Tabel 2. Hasil uji sterilitas

\begin{tabular}{|c|c|c|c|c|c|c|c|c|c|c|c|c|c|c|c|c|c|c|c|}
\hline \multirow{3}{*}{$\begin{array}{c}\begin{array}{c}\text { Durasi } \\
\text { (menit) }\end{array} \\
30\end{array}$} & \multicolumn{15}{|c|}{ Suhu } & \multirow{2}{*}{\multicolumn{3}{|c|}{$\begin{array}{l}\text { Koutrol } \\
\text { negztif }\end{array}$}} & \multirow{3}{*}{$\begin{array}{c}\begin{array}{c}\text { Koutrol } \\
\text { media }\end{array} \\
-\end{array}$} \\
\hline & \multicolumn{3}{|c|}{$130(\mathrm{C})$} & \multicolumn{3}{|c|}{$140(\mathrm{C})$} & \multicolumn{3}{|c|}{$150(\mathrm{C})$} & \multicolumn{3}{|c|}{$160(\mathrm{C})$} & \multicolumn{3}{|c|}{$170(\mathrm{C})$} & & & & \\
\hline & + & + & + & + & + & + & + & + & + & + & + & + & - & & - & + & + & + & \\
\hline 60 & + & + & + & + & + & + & + & + & + & + & $\begin{array}{lll}+ & \\
\end{array}$ & + & - & - & - & + & + & + & - \\
\hline 90 & + & + & + & + & + & + & + & + & + & - & - & - & - & - & - & + & + & + & - \\
\hline 120 & - & - & - & - & - & - & - & - & - & - & - & - & - & - & - & + & + & + & - \\
\hline 150 & - & - & - & - & - & - & - & - & - & - & - & - & - & - & - & + & + & + & - \\
\hline
\end{tabular}

\section{Organoleptik basis gel}

Organoleptik gel penting diamati karena berhubungan dengan estetika gel dan juga penerimaan pasien. Organoleptik basis gel yang diamati meliputi warna, konsistensi, dan bau. Gambar 1 menunjukkan contoh penampilan serbuk alginat setelah disterilisasi pada suhu $170^{\circ} \mathrm{C}$ denga berbagai variasi durasi (Gambar 1a), kemudian didispersikan dalam akuades (Gambar 1b).

Organoleptik basis gel alginat setelah serbuk alginat sebelumnya disterilisasi, secara umum mengalami perubahan. Pada Gambar 1 serbuk alginat yang disterilisasi pada suhu $170^{\circ} \mathrm{C}$ dengan berbagai variasi durasi sterilisasi menunjukkan bahwa semakin lama durasi sterilisasi, warna basis gel yang dihasilkan menjadi lebih gelap, dan konsistensinya semakin cair.

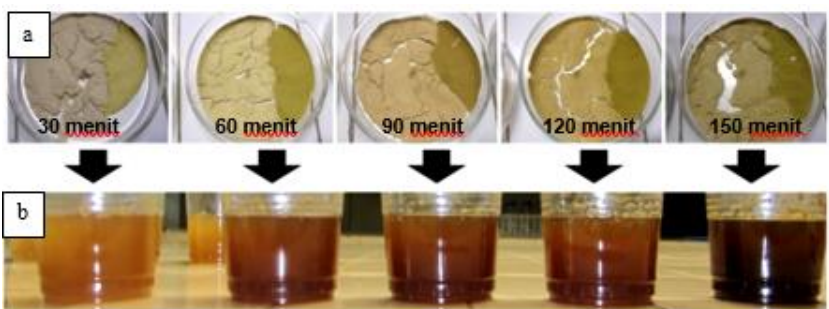

Gambar 1. Penampilan serbuk alginat setelah disterilisasi pada suhu $170^{\circ} \mathrm{C}$ lalu didispersikan dalam air

\section{Sifat fisik basis gel alginat}

Profil $\Delta$ viskositas dan $\Delta$ daya sebar pada berbagai variasi dapat diamati pada Gambar 2. Hasil menunjukkan bahwa semakin tinggi suhu dan durasi sterilisasi, maka $\Delta$ viskositas (Gambar 2a) dan $\Delta$ daya sebar (Gambar 2b) akan meningkat.
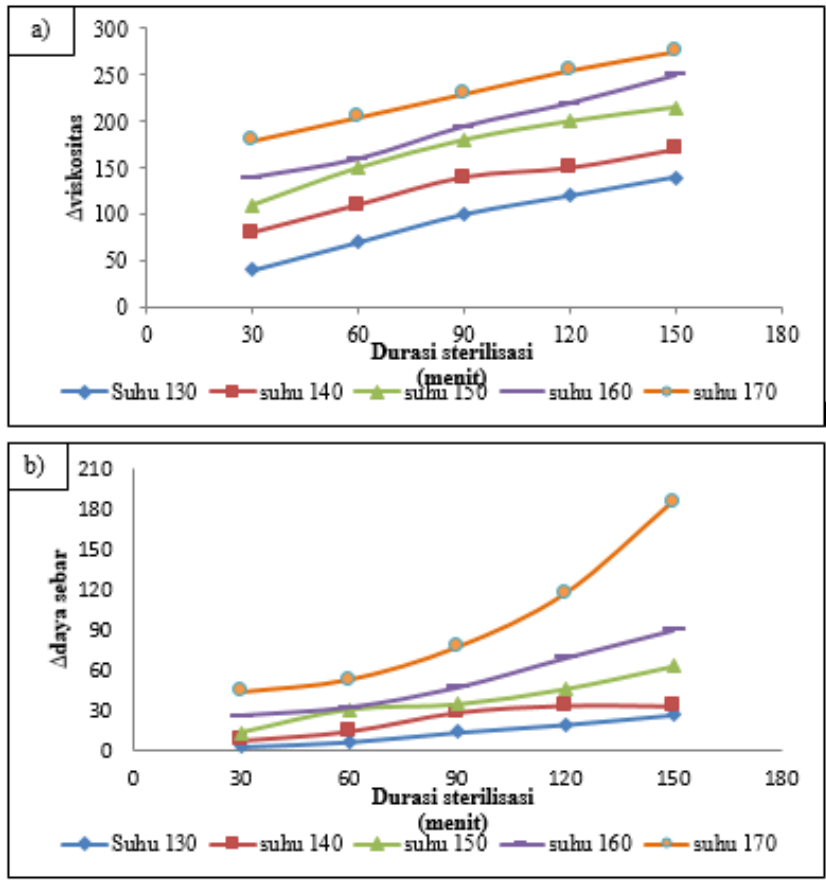

Gambar 2. Profil a) $\Delta$ viskositas dan b) $\Delta$ daya sebar basis gel alginat dengan berbagai variasi suhu dan durasi sterilisasi

Data $\Delta$ viskositas yang diperoleh menunjukkan distribusi yang tidak normal, sehingga diolah menggunakan uji Kruskal-Wallis, sedangkan data $\Delta$ daya sebar yang diperoleh menunjukkan distribusi normal, sehingga diolah menggunakan analisis varian (ANAVA) satu arah. Hasil analisis statistik $\Delta$ viskositas dan $\Delta$ daya sebar pada berbagai variasi suhu dan durasi sterilisasi dapat diamati pada Tabel 3.

Nilai P pada uji beda antara perubahan viskositas dan daya sebar basis gel alginat yang tidak mengalami sterilisasi dan yang mengalami sterilisasi dengan berbagai 
variasi suhu dan durasi sterilisasi adalah kurang dari 0,05. Hal ini menunjukkan bahwa profil viskositas dan daya sebar antara gel yang disterilisasi dan tidak disterilisasi berbeda. Hasil tersebut dapat mengindikasikan bahwa suhu dan durasi sterilisasi mempengaruhi sifat fisik basis gel alginat yang dihasilkan.

Tabel 3. Hasil analisis statistik $\Delta$ viskositas dan $\Delta$ daya sebar basis gel

\begin{tabular}{|c|c|c|c|c|}
\hline \multirow{3}{*}{$\begin{array}{c}\text { Suhu } \\
\text { sterilisasi } \\
\left({ }^{\circ} \mathrm{C}\right)\end{array}$} & \multicolumn{4}{|c|}{ alginat } \\
\hline & \multicolumn{2}{|c|}{$\Delta$ viskositas } & \multicolumn{2}{|c|}{$\Delta$ daya sebar } \\
\hline & Nilai P & Hasil & Nilai P & Hasil \\
\hline 130 & 0,009475 & $\begin{array}{c}\text { Berbeda } \\
\text { bermakna }\end{array}$ & $9,84 \mathrm{e}-12$ & $\begin{array}{c}\text { Berbeda } \\
\text { bermakna }\end{array}$ \\
\hline 140 & 0,009256 & $\begin{array}{c}\text { Berbeda } \\
\text { bermakna }\end{array}$ & $1,22 \mathrm{e}-11$ & $\begin{array}{c}\text { Berbeda } \\
\text { bermakna }\end{array}$ \\
\hline 150 & 0,009819 & $\begin{array}{c}\text { Berbeda } \\
\text { bermakna }\end{array}$ & $1,7 \mathrm{e}-13$ & $\begin{array}{c}\text { Berbeda } \\
\text { bermakna }\end{array}$ \\
\hline 160 & 0,008606 & $\begin{array}{c}\text { Berbeda } \\
\text { bermakna }\end{array}$ & $1,4 \mathrm{e}-11$ & $\begin{array}{c}\text { Berbeda } \\
\text { bermakna }\end{array}$ \\
\hline 170 & 0,008698 & $\begin{array}{c}\text { Berbeda } \\
\text { bermakna }\end{array}$ & $<2 \mathrm{e}-16$ & $\begin{array}{c}\text { Berbeda } \\
\text { bermakna }\end{array}$ \\
\hline 30 & 0,008606 & $\begin{array}{c}\text { Berbeda } \\
\text { bermakna }\end{array}$ & $5,79 \mathrm{e}-15$ & $\begin{array}{c}\text { Berbeda } \\
\text { bermakna }\end{array}$ \\
\hline 60 & 0,01045 & $\begin{array}{c}\text { Berbeda } \\
\text { bermakna }\end{array}$ & $3,03 \mathrm{e}-12$ & $\begin{array}{c}\text { Berbeda } \\
\text { bermakna }\end{array}$ \\
\hline 90 & 0,008606 & $\begin{array}{c}\text { Berbeda } \\
\text { bermakna }\end{array}$ & $2,89 \mathrm{e}-14$ & $\begin{array}{c}\text { Berbeda } \\
\text { bermakna }\end{array}$ \\
\hline 120 & 0,008606 & $\begin{array}{c}\text { Berbeda } \\
\text { bermakna }\end{array}$ & $5,11 \mathrm{e}-16$ & $\begin{array}{c}\text { Berbeda } \\
\text { bermakna }\end{array}$ \\
\hline 150 & 0,008791 & $\begin{array}{c}\text { Berbeda } \\
\text { bermakna }\end{array}$ & $2,67 \mathrm{e}-15$ & $\begin{array}{c}\text { Berbeda } \\
\text { bermakna }\end{array}$ \\
\hline
\end{tabular}

\section{Diskusi}

Alginat adalah salah satu polimer alami yang memiliki berbagai kelebihan sehingga banyak digunakan sebagai sediaan penutup luka. Beberapa diantaranya adalah mudah terdegradasi, tidak toksik, mudah dibersihkan, mampu memberikan kelembaban pada kulit, dan mampu menyerap eksudat luka ${ }^{16}$. Sterilisasi serbuk alginat untuk menghasilkan basis gel sediaan penutup luka yang steril diperlukan agar tidak menimbulkan infeksi pada luka ${ }^{17}$.

Kondisi sterilisasi yang dianjurkan secara umum untuk metode panas kering adalah pada suhu $160^{\circ} \mathrm{C}$ selama 120 menit $^{(10)}$. Hasil uji sterilitas menunjukkan kondisi sterilisasi minimal yang mulai menghasilkan serbuk alginat steril adalah pada suhu $130^{\circ} \mathrm{C}$ selama 120 menit. Efektivitas sterilisasi dengan pemanasan kering dipengaruhi oleh stabilitas aliran udara panas, transfer udara panas ke permukaan objek, serta kandungan lembab pada objek. Perbedaan antara suhu sterilisasi yang dianjurkan dengan suhu minimal pada hasil penelitian dapat dipengaruhi oleh luas permukaan serbuk alginat yang mengalami kontak dengan aliran udara panas. Pada penelitian ini, proses sterilisasi dilakukan dengan menaburkan serbuk alginat pada bidang datar dengan luas permukaan yang besar. Semakin besar luas bidang objek, maka kontak antara udara panas dan objek juga semakin besar. Hal tersebut dapat meningkatkan efektifitas sterilisasi, sehingga diperoleh gel steril pada kondisi sterilisasi dengan suhu dan durasi yang lebih rendah dibandingkan teori.

Sifat fisik gel terutama organoleptik penting untuk diamati terkait dengan estetika basis gel. Perubahan warna yang terjadi pada serbuk alginat setelah mengalami proses sterilisasi, menunjukkan adanya degradasi pada alginat ${ }^{18,19}$. Reaksi hidrolisis asam dan hidrolisis basa merupakan mekanisme utama yang terlibat dalam degradasi serbuk alginat akibat pemanasan ${ }^{(20)}$. Semakin lama durasi sterilisasi pada suhu yang tinggi, maka resiko terjadinya perubahan warna menjadi lebih gelap juga semakin besar ${ }^{21}$.

Semakin tinggi suhu dan durasi sterilisasi dapat meningkatkan $\Delta$ viskositas dan $\Delta$ daya sebar. Kenaikan $\Delta$ viskositas menunjukkan besarnya perbedaan viskositas basis gel alginat yang tidak mengalami sterilisasi dan yang mengalami sterilisasi. Perubahan yang terjadi berupa penurunan viskositas basis gel alginat. Perubahan viskositas, secara langsung akan berdampak pula pada daya sebar basis gel alginat. Kenaikan $\Delta$ daya sebar menunjukkan besarnya perbedaan daya sebar basis gel alginat yang tidak mengalami sterilisasi dan yang mengalami sterilisasi. Perubahan yang terjadi berupa peningkatan nilai daya sebar basis gel.

Penurunan viskositas dan peningkatan daya sebar basis gel alginat merupakan dampak dari proses sterilisasi. Hal ini disebabkan karena adanya pemutusan rantai polimer (depolimerisasi) ketika mengalami pemanasan ${ }^{11,22}$. Sterilisasi dengan oven (panas kering) melibatkan pemanasan yang dapat menyebabkan depolimerisasi pada alginat akibat oksidasi pada asam uronat, dan kerusakan stuktur egg box ${ }^{11,23}$. Mekanisme depolimerisasi lain yang mungkin terjadi adalah akibat hidrolisis asam dan basa pada saat serbuk alginat mengalami pemanasan ${ }^{(20)}$. Hal ini tentu akan berdampak pada viskositas dan daya sebar basis gel alginat.

Perubahan pada sifat fisik basis gel alginat setelah mengalami sterilisasi harus dipertimbangkan, karena bagaimanapun juga basis gel yang dihasilkan harus tetap steril. Berdasarkan profil sterilitas dan sifat fisik yang dimunculkan pada Tabel II dan Gambar 2, maka dapat dilihat bahwa kondisi suhu dan durasi sterilisasi yang memberikan perubahan viskositas serta daya sebar paling kecil adalah pada $130^{\circ} \mathrm{C}$ selama 120 menit.

Dari hasil dan paparan di atas, maka dapat disimpulkan bahwa sterilisasi alginat dengan panas kering pada suhu tinggi dan durasi yang lama berpengaruh terhadap sifat fisik basis gel yang terbentuk, yaitu warna yang menjadi lebih gelap, penurunan viskositas, dan peningkatan daya sebar. Suhu terendah dan durasi tersingkat proses sterilisasi panas kering pada serbuk alginat dengan $\Delta$ viskositas dan $\Delta$ daya sebar terendah pada basis gel alginat yang dihasilkan adalah sterilisasi suhu $130^{\circ} \mathrm{C}$ selama 120 menit.

\section{Daftar Pustaka}

1. Direktorat Jenderal Bina Kefarmasian dan Alat Kesehatan. Pedoman Penggunaan Obat Bebas dan 
Bebas Terbatas. Jakarta. Direktorat Jenderal Bina Kefarmasian dan Alat Kesehatan; 2006.

2. Weir, D. How to... Top Tips for wound dressing selection. Wounds Middle East. 2014;1(1):24-26.

3. Boateng JS, Mattews KH, Stevens HN, Eccleston GM. Wound healing dressings and drug delivery systems: a review. Journal of Pharmaceutical Sciences. 2008;97(8):2892-2923.

4. Saarai A, Kasparkova V, Sedlacek T, Saha P. A comparative study of crosslinked sodium alginate/gelatin hydrogels for wound dressing. In: Proceedings of the 4th WSEAS international conference on Energy and DevelopmentEnvironment-Biomedicine. World Scientific and Engineering Academy and Society (WSEAS); 2011. p. 384-389.

5. Serp D, Mueller M, Von Stockar U, Marison IW. Low-temperature electron microscopy for the study of polysaccharide ultrastructures in hydrogels: II. Effect of temperature on the structure of Ca2+alginate beads. Biotechnology and Bioengineering. 2002;79(3):253-259.

6. Rehm BH. Alginates: biology and applications. Springer Science \& Business Media; 2009

7. Lee KY, Mooney DJ. Alginate: properties and biomedical applications. Progress in Polymer Science. 2012 Jan;37(1):106-26.

8. Draget KI, Smidsrød O, Skjåk-Broek G. Polysaccharides and Polyamides in The Food Industry: Properties, Production, and Patents. Weinheim: Wiley; 2015. 4, 13.

9. Block SS. Disinfection, Sterilization, and Preservation. Lippincott Williams \& Wilkins; 2001. $1432 \mathrm{p}$.

10. Fraise AP, Lambert PA, Maillard J-Y. Russell, Hugo $\&$ Ayliffe's Principles and Practice of Disinfection, Preservation \& Sterilization. Victoria: John Wiley \& Sons; 2008.

11. Leo WJ, McLoughlin AJ, Malone DM. Effects of sterilization treatments on some properties of alginate solutions and gels. Biotechnology Progress. 1990;6(1):51-53.

12. Garg A, Aggarwal D, Garg S, Singla AK. Spreading of semisolid formulations: an update. Pharmaceutical Technology. 2002;26(9):84-105.

13. Barry BW. Rheology of pharmaceutical and cosmetic semisolids. Advances in Pharmaceutical Sciences. 1974;4:1-72.

14. Sari R, Isadiartuti D,. Studi efektivitas sediaan gel antiseptik tangan ekstrak daun sirih (Piper betle Linn.). Majalah Farmasi Indonesia, 2006, 17.4: 163169.

15. Kumar L, Verma R. In vitro evaluation of topical gel prepared using natural polymer. International journal of drug delivery. 2010;2(1).
16. Stephen AM, Phillips GO. Food Polysaccharides and Their Applications. CRC Press; 2016. 750 p.

17. Kujath P, Michelsen A. Wounds from physiology to wound dressing. Deutsches Arzteblatt-Koln. 2008;105(13):239.

18. Nagasawa N, Mitomo H, Yoshii $\mathrm{F}$, Kume $\mathrm{T}$. Radiation-induced degradation of sodium alginate. Polymer Degradation and Stability. 2000;69(3):279285.

19. Smidsrod O, Haug A, Larsen B. Degradation of alginate in the presence of reducing compounds. Acta Chemical Scandinavia. 1963;17(10):2628-2637.

20. Holme HK, Lindmo K, Kristiansen A, Smidsrød O. Thermal depolymerization of alginate in the solid state. Carbohydrate Polymers. 2003;54(4):431-438.

21. Oates CG, Ledward DA. Studies on the effect of heat on alginates. Food Hydrocolloids. 1990;4(3):215220.

22. Bindal A, Narsimhan G, Hem SL, Kulshreshtha A. Effect of steam sterilization on the rheology of polymer solutions. Pharmaceutical Development and Technology. 2003;8(3):219-228.

23. Gomez CG, Rinaudo M, Villar MA. Oxidation of sodium alginate and characterization of the oxidized derivatives. Carbohydrate Polymers. 2007 Feb 1;67(3):296-304. 